\title{
Isotretinoin-like syndrome
}

\author{
INSERM
}

\section{Source}

INSERM. (1999). Orphanet: an online rare disease and orphan drug data base.

Isotretinoin-like syndrome. ORPHA:2306

Isotretinoin-like syndrome is a phenocopy of the isotretinoin embryopathy. 